\title{
Prevalence of hearing loss and tinnitus in a group of adults with Human Immunodeficiency Virus
}

\begin{tabular}{|c|c|}
\hline $\begin{array}{l}\text { Authors: } \\
\text { Alison Millar }^{1} \\
\text { Karin Joubert }^{1} \\
\text { Alida Naude }^{3}\end{array}$ & \\
\hline $\begin{array}{l}\text { Affiliations: } \\
{ }^{1} \text { Department } 0 \\
\text { Pathology and } \\
\text { University of th } \\
\text { Johannesburg, }\end{array}$ & $\begin{array}{l}\text { fpeech } \\
\text { Audiology, } \\
\text { Witwatersrand, } \\
\text { South Africa }\end{array}$ \\
\hline $\begin{array}{l}{ }^{2} \mathrm{Ndlovu} \text { Wits } \\
\text { and Outreach } \\
\text { Dennilton, So }\end{array}$ & $\begin{array}{l}\text { Audiology Clinic } \\
\text { Programme, } \\
\text { th Africa }\end{array}$ \\
\hline $\begin{array}{l}{ }^{3} \text { Centre for Au } \\
\text { Alternative Co } \\
\text { Faculty of Hun } \\
\text { University of } \\
\text { Pretoria, Sout }\end{array}$ & $\begin{array}{l}\text { gmentative and } \\
\text { mmunication, } \\
\text { lanities, } \\
\text { retoria, } \\
\text { Africa }\end{array}$ \\
\hline $\begin{array}{l}\text { Correspondin } \\
\text { Alison Millar, } \\
\text { millar.ali@gm }\end{array}$ & $\begin{array}{l}\text { author: } \\
\text { il.com }\end{array}$ \\
\hline $\begin{array}{l}\text { Dates: } \\
\text { Received: } 041 \\
\text { Accepted: } 06 \\
\text { Published: } 04\end{array}$ & $\begin{array}{l}\text { Mar. } 2019 \\
\text { lug. } 2019 \\
\text { eeb. } 2020\end{array}$ \\
\hline $\begin{array}{l}\text { How to cite th } \\
\text { Millar, A., Joub } \\
\text { Naude, A. (202 } \\
\text { of hearing loss } \\
\text { group of adults } \\
\text { Immunodeficie } \\
\text { African Journa } \\
\text { Communicatio } \\
67(1), \text { a631. ht } \\
\text { org/10.4102/s }\end{array}$ & $\begin{array}{l}\text { is article: } \\
\text { ert, K., \& } \\
\text { 0). Prevalence } \\
\text { and tinnitus in a } \\
\text { with Human } \\
\text { ncy Virus. South } \\
\text { of } \\
\text { Disorders, } \\
\text { ps://doi. } \\
\text { jcd.v67i1.631 }\end{array}$ \\
\hline $\begin{array}{l}\text { Copyright: } \\
\text { (C) 2020. The } \\
\text { Licensee: AOS } \\
\text { is licensed un } \\
\text { Creative Comr } \\
\text { Attribution Lic }\end{array}$ & $\begin{array}{l}\text { uthors. } \\
\text { S. This work } \\
\text { ler the } \\
\text { lons } \\
\text { ense. }\end{array}$ \\
\hline Read online: & \\
\hline 口itin & $\begin{array}{l}\text { Scan this QR } \\
\text { code with your } \\
\text { smart phone or } \\
\text { mobile device } \\
\text { to read online. }\end{array}$ \\
\hline
\end{tabular}

Background: The Human Immunodeficiency Virus (HIV) has become a global pandemic. With the improvement of antiretroviral (ARV) treatment regimens, life-expectancy of HIV-positive individuals has increased. HIV literature suggests that head and neck manifestations may be the first indication of supressed immunity. Therefore, research regarding the effects of HIV and new treatment regimens on auditory function remains a priority.

Objectives: To describe the audiological characteristics and determine the prevalence of hearing loss and tinnitus in a group of HIV-positive individuals on ARV treatment residing in a rural province.

Methods: The study employed a cross-sectional descriptive research design. Participants were recruited from the clinic and pharmacy waiting areas of a medical centre in a rural area of Limpopo province, South Africa. Two participant groups, an HIV-positive group $\left(N_{1}=60\right)$ and an HIV-negative group $\left(N_{2}=32\right)$ were included in the study. The test battery comprised a comprehensive case history and a routine audiological test battery, which included otoscopy, tympanometry and pure tone audiometry $(250 \mathrm{~Hz}$ to $8000 \mathrm{~Hz})$.

Results: No statistically significant difference was found regarding the prevalence of hearing loss in the two participant groups $(p=0.709)$. However, the prevalence of tinnitus was significantly higher in the HIV-positive group $(p=0.05)$.

Conclusion: The insignificant difference in the audiological test battery results found between the two participant groups may be due to improved ARV treatment regimens and management strategies employed at the medical centre. However, the increased prevalence of tinnitus in the HIV-positive group may also be attributed to the ARV regimen and/or the result of subtle damage to the auditory system, which was not identified by the current audiological test battery. More insight may be obtained about the effects of HIV on hearing by employing a longitudinal research design and inclusion of a more ototoxicity sensitive test battery.

Keywords: Human Immunodeficiency Virus; Acquired Immunodeficiency Syndrome; antiretroviral; hearing loss; tinnitus; audiology; rural.

\section{Introduction}

The Human Immunodeficiency Virus (HIV) is one of the most significant pandemics of modern times (Piot \& Quinn, 2013). Although HIV is a global problem, 33.5\% of people living with HIV can be found in sub-Saharan Africa, of which 19.4 million reside in the eastern and southern regions (UNAIDS, 2017). In 2002, HIV prevalence in South Africa was estimated to be 4.25 million, increasing to 7.52 million in 2018. However, when considering population growth, there has been an overall decline in incidence rate from 1.88\% in 2002 to $1.21 \%$ in 2018 (Statistics South Africa, 2018).

The highest HIV burden in South Africa is reported in rural areas (Gaede \& Versteeg, 2011). Limpopo, one of South Africa's most rural provinces, has a reported prevalence of $17.2 \%$ (Human Sciences Research Council, 2017). High HIV prevalence in rural areas may be attributed to, amongst other factors, poor socioeconomic conditions, high unemployment rates and limited access to healthcare services and resources. These challenges adversely affect healthcare provision, which ultimately result in poorer healthcare outcomes for residents in these areas (Gaede \& Versteeg, 2011).

HIV disease has, since the use of antiretrovirals (ARVs), changed from life-threatening to a manageable condition (Heinze, Swanepoel, \& Hofmeyr, 2011). HIV targets the immune system by reducing cluster of differentiation 4 cells (CD4+) or T-lymphocytes (T-cells) (World Health 
Organization (WHO), 2015). An HIV-positive individual may transition through various stages of infection (categories 1 to 3 and $\mathrm{A}, \mathrm{B}$ and $\mathrm{C}$ ) based on the CD4+ count and presence of comorbid conditions. The most advanced stage of infection is known as Acquired Immunodeficiency Syndrome (AIDS) (Centres for Disease Control and Prevention (CDC), 1992). In the absence of ARV treatment, immune function remains supressed and HIV-positive individuals become more susceptible to the development of certain cancers and opportunistic infections (WHO, 2015).

Clinical manifestations involving the head and neck region have been reported as among the first indications of suppressed immunity (Lacovou, Vlastarakos, Papacharalampous, Kampessis, \& Nikolopoulos, 2012). The reported prevalence of complications in the auditory system range from 14\% to 75\% (Chandrasekhar et al., 2000; Khoza \& Ross, 2002; Prasad, Bhojwani, Shenoy, \& Prasad, 2006; Van der Westhuizen, Swanepoel, Heinze, \& Hofmeyr, 2013; Zuniga, 1999). Symptoms indicating involvement of the auditory system may include hearing loss, tinnitus, sensation of aural fullness, otalgia, otorrhoea, headaches, oscilliopsia, nausea and a variety of balance disturbances presenting as vertigo, dizziness, gait instability or disequilibrium (Khoza-Shangase \& Van Rie, 2016; Zingler et al., 2007). These symptoms may be the result of direct damage to certain portions of the auditory and/or vestibular pathway or secondary damage resulting from opportunistic infections or use of ototoxic treatment regimens (Stearn \& Swanepoel, 2010).

Various changes have been made to the HIV treatment guidelines since it was first published by the WHO in 2002. The most notable changes include earlier treatment initiation, the use of safer and less toxic ARV drugs and the inclusion of a single, fixed-dose combination tablet taken only once-daily (OD), which may improve treatment adherence (WHO, 2013, 2015). A variety of studies have suggested that ARVs may be ototoxic (Kakuda, 2000; Khoza-Shangase, 2011; Marra et al., 1997; Mata, Yebra, Tutor de Ureta, Villarreal, \& García, 2000). However, establishing the ototoxic relationship between ARVs and auditory function is intricate due to a range of confounding variables affecting auditory function (KhozaShangase, 2011). These variables may include age (very young or aged $>60$ years); genetic susceptibility; duration of treatment; dosage; simultaneous use of diuretic therapy; cotreatment with other ototoxic drugs; previous history of receiving ototoxic medications or any sensitivity to these medications; impaired renal or hepatic function; pre-existing hearing loss; and history of noise exposure (Bauman, 2003). Contrary to the studies suggesting ototoxicity, a longitudinal prospective study conducted by Schouten and colleagues (2006) suggested that ARVs had no damaging effect on hearing. These authors further suggested that auditory function may be affected by HIV itself; however; hearing may be improved once immune function is strengthened with the use of ARV treatment. A therapeutic role of ARVs has also been suggested by Cohen and colleagues (2012), who reported that these agents had no negative effect on vestibular function. Direct comparison of the results from various ototoxic studies is however difficult, as different test batteries were employed, and thus different portions of the auditory system were evaluated.

As a result of improved ARV protocols and access to treatment, the life expectancy of HIV-positive individuals has increased (Swanepoel \& Louw, 2010). Therefore, research regarding the effects of HIV and new treatment regimens on the auditory and vestibular system remains crucial.

\section{Objectives}

The objectives of this study were to describe the audiological characteristics and determine the prevalence of hearing loss and tinnitus in HIV-positive individuals treated with ARVs residing in a rural community.

\section{Methods}

A cross-sectional, descriptive research design was used to describe the audiological characteristics and determine the prevalence of hearing loss and tinnitus. Participants were recruited from the Ndlovu Medical Centre (NMC) situated in Elandsdoorn, a rural settlement in the Elias Motsoaledi Local Municipality of the Sekhukhune District (Limpopo province, South Africa). This non-governmental organisation has provided free integrated Primary Health Care to HIV-positive individuals since 1994 (Ndlovu Care Group, 2015).

\section{Participants}

The first group comprised HIV-positive individuals $\left(N_{1}=60\right)$ and the control group, HIV-negative individuals $\left(N_{2}=32\right)$ (Table 1). Participants were aged between 18 and 50 years. The age limit was set at 50 years to eliminate the possible impact of the natural ageing process on the auditory system (Huang \& Tang, 2010). All participants in the study were black Africans and the majority were Sepedi first language speakers. Most of participants resided in the Sekhukhune district and were from a disadvantaged socioeconomic background.

The 1992 revised CDC classification system was used to determine the progressive stage of infection of participants in the HIV-positive group (Appendix 1). Most participants in the HIV-positive group $\left(58 \% ; N_{1}=35\right)$ were in category A, with a further $18 \%\left(N_{1}=11\right)$ in category $\mathrm{B}$, and the remainder $\left(23 \% ; N_{1}=14\right)$ in category C. Participants were on a wide variety of ARV protocols, with $88 \%\left(N_{1}=53\right)$ on first-line ARV regimens. Of these, $50 \%\left(N_{1}=30\right)$ were on a first-line fixeddose combination treatment consisting of Efavirenz, Emtricitabine and Tenofovir disoproxil fumarate.

\section{Data collection protocol}

Participants were recruited from the clinic and pharmacy waiting areas of the NMC using a purposive sampling strategy. Only participants who gave written consent were included in the study. 
TABLE 1: Participants' description.

\begin{tabular}{|c|c|c|c|c|c|c|c|c|}
\hline \multirow[t]{3}{*}{ Participant group } & \multirow[t]{3}{*}{$N$} & \multicolumn{3}{|c|}{ Age (in years) } & \multicolumn{4}{|c|}{ Gender } \\
\hline & & \multirow[t]{2}{*}{ Mean } & \multirow[t]{2}{*}{ Range } & \multirow[t]{2}{*}{ SD } & \multicolumn{2}{|c|}{ Male } & \multicolumn{2}{|c|}{ Female } \\
\hline & & & & & $n$ & $\%$ & $n$ & $\%$ \\
\hline HIV-positive & 60 & 41.4 & $23-50$ & 5.3 & 20 & 33 & 40 & 67 \\
\hline Control & 32 & 32.5 & $18-50$ & 9.1 & 9 & 28 & 23 & 72 \\
\hline
\end{tabular}

SD, standard deviation.

Data collection protocol comprised a review of HIV-positive participants' medical records (CD4 count, presence of comorbid conditions, ARV protocol and treatment duration) to guide the classification of HIV-positive participants according to the CDC category. For the two participant groups, a comprehensive case history (medical and audiological) and routine audiological examination were conducted. The audiological test battery was conducted on site at the Ndlovu Wits Audiology Clinic. All equipment was calibrated prior to the commencement of the study (SABS 0154-1; 0154-2). The test battery included otoscopy (Heine Mini 3000 otoscope), tympanometry using a $226 \mathrm{~Hz}$ frequency probe tone (Interacoustics Titan tympanometer) and standard pure tone audiometry (Interacoustics Diagnostic Audiometer: AD629). A normal type A tympanogram was classified according to the following criteria: ear canal volume: 0.8 to $2.0 \mathrm{~mL}$; static compliance: 0.3 to $1.8 \mathrm{~mL}$; middle ear pressure: $-100 \mathrm{daPa}$ to $+50 \mathrm{daPa}$ (Jerger, 1970). Air conduction thresholds were obtained via headphones $(250 \mathrm{~Hz}$ to 8000 $\mathrm{Hz}$ ) for both ears. The air conduction thresholds obtained at $500 \mathrm{~Hz}, 1 \mathrm{kHz}$ and $2 \mathrm{kHz}$ were used to calculate the Pure Tone Average (PTA). Bone conduction testing was conducted when air conduction thresholds exceeded $25 \mathrm{~dB}$ HL at any frequency between and including $250 \mathrm{~Hz}$ and $4000 \mathrm{~Hz}$. These thresholds were obtained by placing the bone vibrator on one mastoid at a time, in the case of a bilateral impairment, or one side only in the case of a unilateral impairment. Pure tone audiometry results were classified as within normal limits based on a PTA of $\leq 25 \mathrm{~dB}$ HL. Therefore, a PTA of $>25$ $\mathrm{dB}$ HL was considered a hearing loss. The hearing loss was categorised as conductive, sensorineural, mixed or a hearing loss at only a specific frequency (e.g. abnormal threshold of $>25 \mathrm{~dB}$ HL at $8 \mathrm{kHz}$ ).

\section{Data analysis}

The data analysis was performed using SAS Release 9.4 (SAS Institute Inc., Carey, NC, USA). Descriptive statistics were used to describe measures of central tendencies (mean value) as well as measures of variability (i.e. range and standard deviation [SD]). The Fisher's exact test was used to establish significance of percentages between the two participant groups. This test was also used to establish whether prevalence of tinnitus between the various CDC categories (1-3) was significant. For probability tests, $p \leq 0.05$ was considered statistically significant.

\section{Ethical consideration}

Data collection commenced once ethical clearance was obtained from the Human Research Ethics Committee

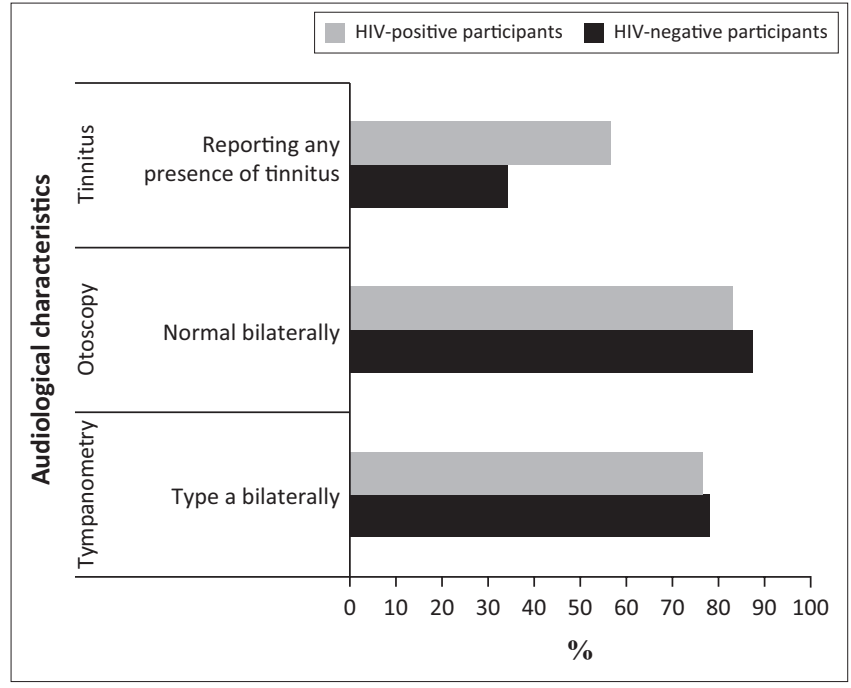

FIGURE 1: Most prevalent audiological characteristics in the two participant groups (HIV-positive participants $\left[N_{1}=60\right]$ and HIV-negative participants $\left[N_{2}=32\right]$ ).

(Medical) of the University of the Witwatersrand (Protocol number: M160150) and permission was granted by the Limpopo Department of Health and Social Development.

\section{Results}

\section{Audiological characteristics}

Self-reported auditory symptoms (such as hearing loss, otalgia and a blocked-ear sensation) were reported in $33 \%$ $\left(N_{1}=20\right)$ of HIV-positive participants and $25 \%\left(N_{2}=8\right)$ of the control group. Difference in the prevalence of these symptoms between the two groups was not statistically significant ( $p=0.481$; Fisher's exact test).

A majority of participants in both groups presented with normal otoscopy, tympanometry (Figure 1) and pure tone results with hearing $<30 \mathrm{~dB}$ HL bilaterally. Pure tone results were symmetrical in $83 \%\left(N_{1}=50\right)$ of HIV-positive participants and $91 \%\left(N_{2}=29\right)$ of the control group. A summary of the presence and nature of hearing loss in participants of the current study are presented in Table 2.

The prevalence of abnormal otoscopy between the two groups was not statistically significant ( $p=0.177$; Fisher's exact test), and neither was abnormal middle ear function, as suggested by tympanometry $(p=1.000$; Fisher's exact test).

\section{Prevalence of hearing loss}

The mean PTA (dB HL) was similar in both groups. The HIV-positive group obtained a mean PTA of $12.6 \mathrm{~dB}$ HL and $12.3 \mathrm{~dB}$ HL in the left and right ears respectively. In the control group, the PTA was $11.4 \mathrm{~dB}$ HL in the left ear and $13.7 \mathrm{~dB} H \mathrm{HL}$ in the right. The prevalence of hearing loss was $10 \%\left(N_{1}=6\right)$ in the HIV-positive group and $6 \%\left(N_{2}=2\right)$ in the HIV-negative control group. This difference was not significant ( $p=0.709$; Fisher's exact test). 
TABLE 2: Presence and nature of hearing loss.

\begin{tabular}{|c|c|c|c|c|c|c|c|c|}
\hline \multirow[t]{3}{*}{ Type of hearing loss } & \multicolumn{4}{|c|}{$\begin{array}{l}\text { HIV-positive group } \\
\left(N_{1}=60 ; 120 \text { ears }\right)\end{array}$} & \multicolumn{4}{|c|}{$\begin{array}{l}\text { HIV-negative group } \\
\left(N_{2}=32 ; 64 \text { ears }\right)\end{array}$} \\
\hline & \multicolumn{2}{|c|}{ Left ear } & \multicolumn{2}{|c|}{ Right ear } & \multicolumn{2}{|c|}{ Left ear } & \multicolumn{2}{|c|}{ Right ear } \\
\hline & $\%$ & $n$ & $\%$ & $n$ & $\%$ & $n$ & $\%$ & $n$ \\
\hline Conductive hearing loss & 0 & 0 & 2 & 1 & 0 & 0 & 3 & 1 \\
\hline SNHL & 2 & 1 & 2 & 1 & 6 & 2 & 13 & 4 \\
\hline Mixed hearing loss & 7 & 4 & 3 & 2 & 0 & 0 & 0 & 0 \\
\hline Hearing loss (>25 dB HL) only at specific frequencies & 8 & 5 & 8 & 5 & 3 & 1 & 3 & 1 \\
\hline
\end{tabular}

SNHL, Sensorineural hearing loss.

TABLE 3: Prevalence of hearing loss and tinnitus in the current study in comparison to previous studies.

\begin{tabular}{|c|c|c|c|c|c|c|c|c|c|c|c|c|}
\hline \multirow[t]{2}{*}{ Symptom } & \multicolumn{3}{|c|}{$\begin{array}{l}\text { Current study } \\
\quad(n=60)\end{array}$} & \multicolumn{3}{|c|}{$\begin{array}{l}\text { Chandrasekhar et al. (2000) } \\
(n=51)\end{array}$} & \multicolumn{3}{|c|}{$\begin{array}{l}\text { Khoza and Ross (2002) } \\
(n=150)\end{array}$} & \multicolumn{3}{|c|}{$\begin{array}{l}\text { Van der Westhuizen et al. (2013) } \\
\qquad(n=200)\end{array}$} \\
\hline & $\%$ & $n$ & $p$ & $\%$ & $n$ & $p$ & $\%$ & $n$ & $p$ & $\%$ & $n$ & $p$ \\
\hline Hearing loss & 10 & 6 & - & 29 & 15 & $0.0135^{*}$ & 23 & 35 & $0.0333 *$ & 14 & 28 & 0.5163 \\
\hline Tinnitus & 57 & 34 & - & 26 & 13 & $0.0018^{*}$ & 23 & 35 & $<0.0001 *$ & 26 & 52 & $<0.0001^{*}$ \\
\hline
\end{tabular}

*, Statistically significant ( $\leq 0.05 p$-values were considered significant; Fisher's exact test) when compared to the prevalence of the current study.

\section{Prevalence of tinnitus}

Tinnitus was reported by participants of both groups (Figure 1). Bilateral high frequency, intermittent tinnitus was most frequently reported in both groups. Bilateral tinnitus was reported by $48 \%$ of HIV-positive participants $\left(N_{1}=29\right)$ and unilateral tinnitus was reported by only $8 \%$ $\left(N_{1}=5\right)$. The overall prevalence of tinnitus in the HIVpositive group was $57 \%\left(N_{1}=34\right)$ and in the control group, $34 \%\left(N_{2}=11\right)$. Tinnitus reported in the control group was bilateral in nature. This difference was statistically significant ( $p=0.05$; Fisher's exact test). The prevalence of tinnitus between different CDC categories increased at more progressive stages of infection (CDC category 1 (50\%); CDC category 2 (65\%) and CDC category 3 (53.9\%). However, based on the statistical analysis, this increase was not significant ( $p=0.633$; Fisher's exact test).

\section{Discussion}

\section{Prevalence of hearing loss}

The $10 \%$ hearing loss ( $>25 \mathrm{~dB}$ HL) in HIV-positive individuals and $6 \%$ in the control group is lower than the $19.88 \%$ hearing loss prevalence in the general population as reported for the Elias Motsoaledi Municipality (Joubert \& Botha, 2019). The findings of the current study do not suggest a high prevalence of hearing loss in HIV-positive individuals (Table 3 ) and are similar to the findings reported by Van der Westhuizen et al. (2013). The difference in findings may be attributed to the CDC category of participants, the test battery employed as well as the criteria used to classify hearing loss.

Most of the participants in the current study $\left(58 \%\right.$; $\left.N_{1}=53\right)$ were classified as CDC category A, suggesting that they were asymptomatic and did not present with any secondary conditions. Contrary to this, in the study conducted by Chandrasekhar and colleagues (2000), the majority of participants were in CDC categories B (38\%) and C (44\%), whilst the minority were classified as CDC category A participants (18\%). Similarly, Khoza and Ross (2002) also reported that the majority (91\%) of HIV-positive participants in their study presented with secondary conditions. The prevalence of significantly higher hearing loss reported by these studies (Table 3) may be attributed to the higher prevalence of secondary conditions and medications used to treat these conditions.

The comparable hearing thresholds between the two participant groups in the current study may pertain to the ARV regimen used. The majority of participants were on a first-line ARV regimen, which has been associated with less toxicity (WHO, 2013) and improved treatment adherence due to its once-daily dosing (WHO, 2016). Furthermore, all participants were treated according to new ARV guidelines where treatment is initiated much earlier, irrespective of $\mathrm{CD} 4+$ count or progressive stage of infection. In addition, the NMC, where the study was conducted, employs strict monitoring protocols involving regular blood tests as well as counselling sessions. Therefore, as more emphasis is placed on the follow-up care, treatment adherence levels may have been more optimal, ultimately contributing to reduced auditory damage. The prevalence of slightly higher hearing loss reported by an earlier study $(14 \% ; n=28$; Van der Westhuizen et al., 2013) may have been attributed to the fact that only participants in CDC category $\mathrm{C}$ were receiving ARVs. Thus, the therapeutic effect of ARVs may have limited the destructive effects of HIV on the auditory system in the current study. These findings have also previously been suggested (Cohen et al., 2012; Schouten et al., 2006).

The audiological test batteries used in previous studies included additional measures such as auditory brainstem response audiometry (Khoza \& Ross, 2002) or otoacoustic emissions (OAEs) (Van der Westhuizen et al., 2013). These measures may have been more sensitive at detecting auditory damage. The prevalence of reduced hearing loss in the current study may also be related to the criteria used to classify hearing loss. For example, a previous study (Khoza \& 
Ross, 2002) classified hearing loss as any frequency with a threshold of $>25 \mathrm{~dB} H \mathrm{HL}$, whilst the current study based the criteria on the PTA. However, if frequency-specific criteria were used in the current study, the prevalence of hearing loss would be higher $\left(22 \% ; N_{1}=13\right)$. Furthermore, the reduced prevalence of SNHL in the current study may be explained by the fact that hearing loss which only affected specific higher frequencies (e.g. $8 \mathrm{kHz}$ ) was not classified as sensorineural in nature. This type of configuration was classified in a separate category, whilst other studies may have described such configuration as SNHL.

\section{Prevalence of tinnitus}

The most significant finding of the current study was the increased prevalence of tinnitus in the HIV-positive group. This prevalence was also significantly higher than reported in previous studies (Table 3). The high prevalence in the current study may be attributed to the inclusion of more detailed tinnitus categories. Therefore, participants may have been more likely to report tinnitus even if it was only experienced intermittently or in a different pitch than the more common 'high frequency ringing'. It may however be possible that the increased prevalence of tinnitus may be a result of subtle damage to the auditory pathway, which was not detectable with conventional audiometry.

Similar to the findings reported by Van der Westhuizen et al. (2013), the prevalence of tinnitus was higher in CDC categories 2 and 3 compared to CDC category 1. Although this increase was not statistically significant, this finding may represent progressive damage caused by HIV during more advanced stages of infection (Van der Westhuizen et al., 2013). As tinnitus may present as a symptom of hearing loss, it would be expected that self-reported hearing loss would also be more prevalent in the HIV-positive group. The finding that hearing loss was not reported as frequently as tinnitus, may be attributed to tinnitus being related to non-auditory pathologies, or if the tinnitus is related to hearing loss, the nature or configuration may be more discreet and not always recognised or reported by the individual (Khoza-Shangase \& Van Rie, 2016). Although high-frequency tinnitus was reported by $50 \%\left(N_{1}=4\right)$ of HIV-positive participants with high-frequency hearing loss, this type of tinnitus was also reported by HIV-positive participants with hearing that was within normal limits. As the pitch of tinnitus may represent the hearing frequency most affected (Castillo \& Roland, 2007), the inclusion of high-frequency audiometry $(>8 \mathrm{kHz})$ may have identified more participants presenting with hearing loss.

\section{Conclusion}

Comparable audiological results were found in the two participant groups. However, the prevalence of tinnitus was more significant in the HIV-positive group. Results from the current study warrant the need for longitudinal research to obtain insight regarding the causal relationship between HIV, its treatment regimen and audiological characteristics. These studies, especially if conducted in rural settings, may consider the use of mHealth technologies such as smartphoneautomated pure-tone audiometry. These tests may prove to be more time-efficient when used for regular audiological monitoring purposes, ultimately allowing more individuals to be tested in a shorter amount of time (Brittz, Heinze, Mahomed-Asmail, Swanepoel, \& Stoltz, 2018). To increase the generalisability of results, future studies should include participant groups with similar sample sizes, which are ageand gender-matched. The inclusion of an ototoxicity sensitive test battery (e.g. otoacoustic emissions test or high-frequency audiometry of $>8 \mathrm{kHz}$ ) may also be valuable to evaluate the effects of new ARV regimens, treatment adherence levels and effective follow-up care on hearing status. As tinnitus was a prevalent finding in the HIV-positive group, research should place more emphasis on this area.

\section{Acknowledgements}

The authors thank Ndlovu Medical Centre for allowing the use of their audio-clinic and facility to retrieve participants. This article is based on the dissertation submitted by A.M. to the University of the Witwatersrand, Johannesburg, South Africa.

\section{Competing interests}

The authors declare that no financial interests or personal relationships are involved that may have inappropriately influenced the writing of this article.

\section{Authors' contributions}

A.M. was the principal investigator, co-conceptualised and designed the study and drafted the manuscript. K.J and A.N. co-conceptualised and designed the study, supervised the project and reviewed the manuscript. All three authors read and approved the final version of the manuscript and have approved its submission for publication.

\section{Funding information}

This research received no specific grant from any funding agency in the public, commercial, or not-for-profit sectors.

\section{Data availability statement}

The data that support the findings of this article are openly available from http:/ / wiredspace.wits.ac.za/handle/10539/ 26552.

\section{Disclaimer}

The views and opinions expressed in this article are those of the authors and do not necessarily reflect the official policy or position of any affiliated agency of the authors.

\section{References}

Bauman, N.G. (2003). Ototoxicity - The hidden menace. Part I: Lives in upheaval. Retrieved from http://www.hearnet.com/features/articles/Ototoxic_Drugs_Exposed.pdf. 
Brittz, M., Heinze, B., Mahomed-Asmail, F., Swanepoel, D.W., \& Stoltz, A. (2018) Monitoring hearing in an infectious disease clinic with mHealth technologies. Journal of the American Academy of Audiology, 30(6), 482-492. https://doi. org/10.3766/jaaa.17120
Journal of the American

Castillo, M.P., \& Roland, P.S. (2007). Disorders of the auditory system. In R.J. Roeser, M Valente, \& H. Hosford-Dunn (Eds.), Audiology diagnosis (p. 378). Stuttgart: Thieme Medical Publishers.

Centres for Disease Control and Prevention (CDC). (1992). Revised classification system for HIV infection and expanded surveillance case definition for AIDS Among Adolescents and Adults. Retrieved from https://www.who.int/hiv/strategic/en/ cdc_1993_hivaids_def.pdf.

Chandrasekhar, S.S., Connelly, P.E., Brahmbhatt, S.S., Shah, C.S., Kloser, P.C., \& Baredes, S. (2000). Otologic and audiologic evaluation of human immunodeficiency virusinfected patients. American Journal of Otolaryngology, 21(1), 1-9. https://doi.org /10.1016\%2Fs0196-0709\%2800\%2980117-9

Cohen, H.S., Cox, C., Springer, G., Howard, J.H., Young, M., Margolick, J.B., \& Plankey, M.W. (2012). Prevalence of abnormalities in vestibular function and balance among HIV-seropositive and HIV-seronegative women and men. PLoS One, 7(5), e38419. https://doi.org/10.1371/journal.pone.0038419

Gaede, B., \& Versteeg, M. (2011). The state of the right to health in rural South Africa. South African Health Review. Retrieved from http://www.rhap.org.za/ wp-content/uploads/2014/02/Chap-9-State-of-right-Rural-Healthpgs-99-106. pdf

Heinze, B., Swanepoel, D.W., \& Hofmeyr, L.M. (2011). Systematic review of vestibular disorders related to human immunodeficiency virus and acquired immunodeficiency syndrome. The Journal of Laryngology and Otology, 125(9), 881-890. https://doi.org/10.1017\%2Fs0022215111001423

Huang, Q., \& Tang, J. (2010). Age-related hearing loss or presbycusis. European Archives of Oto-Rhino-Laryngology, 267(8), 1179-1191. https://doi.org/10.1007/ s00405-010-1270-7

Human Sciences Research Council. (2017). HIV impact assessment summary: The fifth South African national HIV prevalence, incidence, behaviour and communication survey. Retrieved from http://www.hsrc.ac.za/uploads/ pageContent/9234/SABSSMV_Impact_Assessment_Summary_ZA_ADS_ cleared_PDFA4.pdf.

Jerger, J. (1970). Clinical experience with impedance audiometry. Archives of Otolaryngology-Head and Neck Surgery, 92(4), 311-324. https://doi.org/10.1001/ archotol.1970.04310040005002

Joubert, K., \& Botha, D. (2019). Contributing factors to high prevalence of hearing impairment in the Elias Motsoaledi Local Municipal area, South Africa: A rura perspective. South African Journal of Communication Disorders, 66(1), 7 pages. https://doi.org.10.4102/sajcd.v66i1.611

Kakuda, T.N. (2000). Pharmacology of nucleoside and nucleotide reverse transcriptase inhibitor-induced mitochondrial toxicity. Clinical Therapeutics, 22(6), 685-708. $\mathrm{https}: / /$ doi.org/10.1016/s0149-2918(00)90004-3

Khoza, K., \& Ross, E. (2002). Auditory function in a group of adults with HIV/AIDS in Gauteng, South Africa. South African Journal of Communication Disorders, 49(1), 17-27. Retrieved from https://journals.co.za/content/communication/49/1 AJA03798046_369.

Khoza-Shangase, K. (2011). Highly active antiretroviral therapy: Does it sound toxic? Journal of Pharmacy and Bioallied Sciences, 3(1), 142-153. https://doi. org/10.4103/0975-7406.76494

Khoza-Shangase, K., \& Van Rie, K.J. (2016). Pathological vestibular symptoms presenting in a group of adults with HIV/AIDS in Johannesburg, South Africa. Southern African Journal of Infectious Diseases, 32(2), 43-53. https://doi.org/10. 1080/23120053.2016.1216816
Lacovou, E., Vlastarakos, P.V., Papacharalampous, G., Kampessis, G., \& Nikolopoulos, T.P. (2012). Diagnosis and treatment of HIV-associated manifestations in otolaryngology. Infectious Disease Reports, 4(1), 9. https://doi.org/10.4081\%2Fidr.2012.e9

Marra, C.M., Wechkin, H.A., Longstreth, W.T., Rees, T.S., Syapin, C.L., \& Gates, G.A. (1997). Hearing loss and antiretroviral therapy in patients infected with HIV-1. Archives of Neurology, 54(4), 407-410. https://doi.org/10.1001/archneur.1997.00550160049015

Mata, C.N., Yebra, B.M., Tutor de Ureta, P., Villarreal, G.L.M., \& García, L.F. (2000). Hearing loss and human immunodeficiency virus infection. Study of 30 patients Revista Clinica Espc

Ndlovu Care Group. (2015). Ndlovu health care. Retrieved from http://www. ndlovucaregroup.co.za/.

Piot, P., \& Quinn, T.C. (2013). Response to the AIDS pandemic - A global health model. New England Journal of Medicine, 368(23), 2210-2218. https://doi. org/10.1056\%2Fnejmra1201533

Prasad, H.K.C., Bhojwani, K.M., Shenoy, V., \& Prasad, S.C. (2006). HIV manifestations in otolaryngology. American Journal of Otolaryngology, 27(3), 179-185. https://doi. org/10.1016\%2Fj.amjoto.2005.09.011

Schouten, J.T., Lockhart, D.W., Rees, T.S., Collier, A.C., \& Marra, C.M. (2006). A prospective study of hearing changes after beginning zidovudine or didanosine in HIV-1 treatment-naïve people. BMC Infectious Diseases, 6(1), 28. https://doi. org/10.1186/1471-2334-6-28

Statistics South Africa. (2018). Mid-year population estimates. Retrieved from http:// www.statssa.gov.za/publications/P0302/P03022018.pdf.

Stearn, N., \& Swanepoel, D.W. (2010). Sensory and neural auditory disorders associated with HIV/AIDS. In D.W. Swanepoel \& B. Louw (Eds.), HIV/AIDS related communication, hearing and swallowing disorders (pp. 243-288). San Diego, CA Plural Publishing.

Swanepoel, D.W., \& Louw, B. (2010). Global perspective on HIV/AIDS and associated communication, hearing and swallowing disorders. In D.W. Swanepoel \& B. Louw (Eds.), HIV/AIDS related communication, hearing and swallowing disorders (pp. 1-10). San Diego, CA: Plural Publishing.

UNAIDS. (2017). Ending AIDS: Progress towards the 90-90-90 targets. Retrieved from http://www.unaids.org/sites/default/files/media_asset/Global_AIDS update_2017_en.pdf.

Van der Westhuizen, Y., Swanepoel, D.W., Heinze, B., \& Hofmeyr, L.M. (2013). Auditory and otological manifestations in adults with HIV/AIDS. International Journal of Audiology, 52(1), 37-43. https://doi.org/10.3109\%2F14992027.2012.721935

World Health Organization (WHO). (2002). Scaling up antiretroviral therapy in resource-limited settings: Guidelines for a public health approach. Geneva: WHO. Retrieved from https://www.who.int/hiv/pub/prevcare/ScalingUPE.pdf

World Health Organization (WHO). (2013). What ART regimen to start with (first-line ART): Consolidated ARV guidelines. Retrieved from http://www.who.int/hiv/pub/ guidelines/arv2013/art/whatregimentostart/en/.

World Health Organization (WHO). (2015). HIV/AIDS. Geneva: WHO. Retrieved from http://www.who.int/mediacentre/factsheets/fs360/en/.

World Health Organization (WHO). (2016). Consolidated guidelines on the use of antiretroviral drugs for treating and preventing HIV infection. Retrieved from http:// apps.who.int/iris/bitstream/10665/208825/1/9789241549684_eng.pdf?ua=1.

Zingler, V.C., Cnyrim, C., Jahn, K., Weintz, E., Fernbacher, J., Frenzel, C., ... Strupp, M. (2007). Causative factors and epidemiology of bilateral vestibulopathy in 255
patients. Annals of Neurology, 61(6), 524-532. https://doi.org/10.1002\%2Fana. patients

Zuniga, J. (1999). Communication disorders and HIV disease. Journal of the International Association of Physicians in AIDS Care, 5(4), 16-23. 


\section{Appendix 1}

TABLE 1-A1: CDC classification system for HIV-infected adults and adolescents.

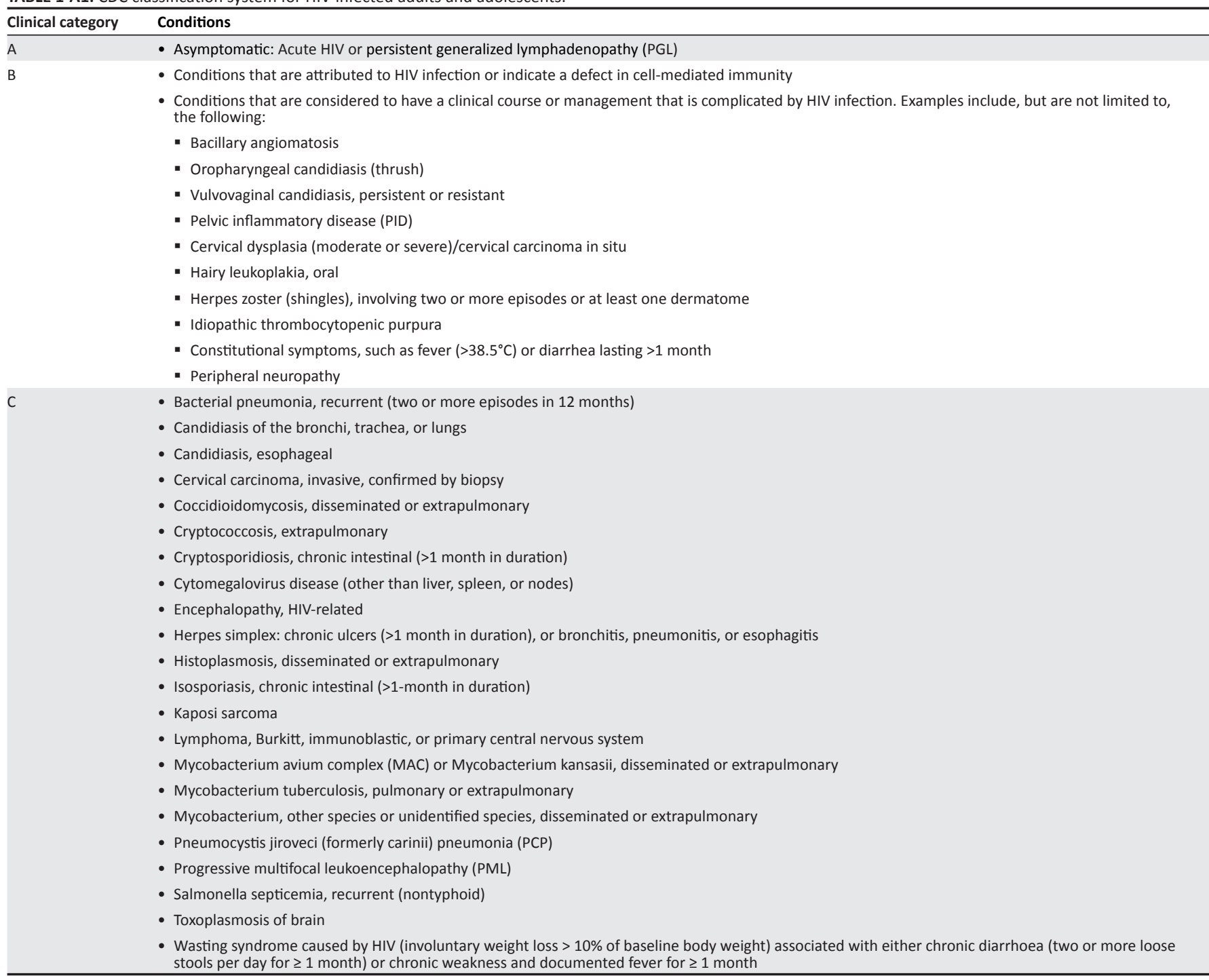

Source: Adapted from Centres for Disease Control and Prevention (CDC). (1992). Revised classification system for HIV infection and expanded surveillance case definition for AIDS Among Adolescents and Adults. Retrieved from https://www.who.int/hiv/strategic/en/cdc_1993_hivaids_def.pdf

TABLE 2-A1: CDC classification system for HIV-infected adults and adolescents.

\begin{tabular}{|c|c|c|c|}
\hline \multirow[t]{2}{*}{ CD4* cell count } & \multicolumn{3}{|c|}{ Clinical categories } \\
\hline & A: Asymptomatic acute HIV or PGL & B: Symptomatic conditions, not A or C & C: AIDS-indicator conditions \\
\hline (1) 500 cells $/ \mu \mathrm{L}$ & A1 & B1 & C1 \\
\hline (2) $200-499$ cells $/ \mu \mathrm{L}$ & $\mathrm{A} 2$ & B2 & C2 \\
\hline (2) 200 cells $/ \mu \mathrm{L}$ & A3 & B3 & C3 \\
\hline
\end{tabular}

Source: Adapted from Centres for Disease Control and Prevention (CDC). (1992). Revised classification system for HIV infection and expanded surveillance case definition for AIDS Among Adolescents and Adults. Retrieved from https://www.who.int/hiv/strategic/en/cdc_1993 hivaids_def.pdf

$\mathrm{CD} 4 *$, cluster of differentiation $4+; \mu \mathrm{L}$, microliter. 